\title{
ORIGINAL
}

PROF-932

\section{HEPATITIS - C}

\author{
DR. NAYLA TARIQ CHAUDRY, M.Phil. \\ Assistant Professor \\ Dept. of Physiology, AIMC, Lahore.
DR. WAHEED JAMEEL, MBBS
Demonstrator, \\ Dept. of Physiology, AIMC, Lahore.
}

\author{
DR. IMRANA IHSAN, M.Phil. \\ Assistant Professor \\ Dept. of Physiology, AIMC, Lahore.
}

Dr. Sabiha Nasreen, MBBS

Associate Prof \& Head,

Dept. of Physiology, AIMC, Lahore.

Copyrights: 25 June, 2005

\begin{abstract}
Objectives: 1) To evaluate the overall prevalence rate of viral hepatitis carrier state among a group of voluntary blood donors. 2) To find the proportion of anti HCV in the study group. 3) To find the probable mode of transmission of HCV infection in the study group. Setting: Pathology lab, Jinnah Hospital, Iqra Medical Complex \& Hi Tech Lab, Lahore. Period: November 2000 to April 2001. Patients \& Methods: A total of 890 apparently healthy blood donors (797 males, 93 females) were studied. Clinical details were recorded. The blood samples were collected using packed sterile disposable syringes. Sera were analysed by a qualitative enzyme immunoassy sera diagnostic test using second generation ELISA Kits. Results: Among 890 subjects screened, carrier state for hepatitis- $C$ was $6.06 \%$. The prevalence of hepatitis-C amongst total cases positive for hepatitis was $33.5 \%$. A higher prevalence rate in males $(6 \sim 8 \%)$ was observed as compared to females $(2.22 \%)$. The difference was statistically significant $(p<0.05$ ). The most important mode of transmission was through injections; (males $32.075 \%$, females $100 \%$ ) followed by blood transfusion. Only $5.88 \%$ of the cases had an episode of jaundice in the past. Conclusion: A remarkable positive cases of hepatitis $\mathrm{C}$ in this study underline the dire need of comprehensive plan for multi-disciplinary approach for HCV prevention and control.
\end{abstract}

\section{INTRODUCTION}

Hepatitis is the bigger killer disease than AIDS, which need to be fought on a war footing. It is a deadly disease with an increasing toll over the years in Pakistan'. Hepatitis infects four times as many people as AIDS worldwide. The World Health Organization estimates that about $3 \%$ of the world population is infected with hepatitis- $\mathrm{C}$ virus $(\mathrm{HCV})^{2}$. Hepatitis- $\mathrm{C}$ infection is caused by HCV that belongs to the Flaviviridae family of viruses, which was identified in $1989^{3}$. Hepatitis-C disease is an inflammation of the liver. The acute hepatitis is mild, HCV has a higher propensity for transition to chronicity causing chronic hepatitis, cirrhosis of liver and causing hepato-cellular carcinoma ${ }^{4,5}$.

$\mathrm{HCV}$ is the most common cause of hepatitis after blood transfusion ${ }^{6}$. Children having multiple transfusions due to chronic anaemia, cancer or haemophilia as well as 
patients on haemodialysis are at a high risk for HCV infection. The reported prevalence range is from 10 to $85 \%{ }^{7,8}$.

Contaminated blood, blood products and body fluids are common mode of transmission of HCV. The other risk factors are intravenous drug abuse, use of barber razor, dental procedures, tattooing, ear piercing, acupuncture and high-risk sexual behaviour ${ }^{\text {. }}$.

This study was undertaken on the cases suspected of having hepatitis among voluntary blood donors. These cases had been analyzed during the period from November 2000 to April 2001, in the Pathology Lab of Jinnah Hospital, Iqra Medical Complex and Hi Tech Lab, Lahore.

\section{AIMS \& OBJECTIVES}

Present study was planned to;

Evaluate the overall prevalence rate of viral hepatitis carrier state among a group of voluntary blood donors.

1. Find the proportion of anti HCV in the study group.

2. Find the probable modes of transmission of $\mathrm{HCV}$ infection in the study group.

\section{SUBJECTS \& METHODS}

In this study a total of 890 voluntary blood donors of either sex were included. The subjects suspected of having hepatitis were tested. The clinical details were recorded. The blood samples were collected by vein puncture using packed, sterile disposable syringes. For sera-diagnosis of type of viral hepatitis, sera were analysed by qualitative enzyme immunoassay sera diagnostic test using second generation ELISA Kits (Abbott).

Statistical analysis was performed on personal computer using software Epilnfo 6. Percentages were calculated \& Fischer's Exact test was used for data analysis. A pvalue less than $0.05(p<0.05)$ was considered statistically significant.

\section{RESULTS}

A total of 890 apparently healthy blood donors, comprising of 797 males and 93 females were studied.

The carrier state for hepatitis was detected in $18.04 \%$ of the subjects. The percentage for hepatitis-A, hepatitis-B and hepatitis-C was $4.15 \%, 7.86 \%$ and $6.06 \%$ respectively as shown in (Table-1).

\begin{tabular}{|c|c|c|c|c|c|}
\hline \multicolumn{7}{|c|}{ Table I. The carrier state for different types of hepatitis } \\
\hline PFTs & Voluntary Blood Donors (n) & $\begin{array}{c}\text { +ve Cases of Hepatitis } \\
(\mathbf{n})\end{array}$ & Hepatitis A (n) & Hepatitis B (n) & Hepatitis C (n) \\
\hline Nov. 2000 & 163 & 29 & 08 & 11 & 10 \\
\hline Dec. 2000 & 204 & 31 & 02 & 17 & 12 \\
\hline Jan. 2001 & 146 & 21 & 04 & 08 & 09 \\
\hline Feb. 2001 & 158 & 22 & 11 & 06 & 05 \\
\hline Mar. 2001 & 154 & 26 & 05 & 14 & 07 \\
\hline Apr. 2001 & 173 & 32 & 07 & 14 & 11 \\
\hline Total & 998 & 161 & 37 & 70 & 54 \\
\hline$\%$ Age & - & 18.04 & 4.15 & 7.86 & 6.06 \\
\hline
\end{tabular}


The proportion of hepatitis- $\mathrm{C}$ amongst the total cases of hepatitis was $33.54 \%$ as given in (Table-2).

Table-III shows that a higher percentage of male subjects $(6.8 \%)$ showed positive results for anti HCV antigen as compared to females (1.07\%). The difference was significant $(p<0.05)$.

The most important mode of transmission was through injections; (males 32.075\%, females 100\%) followed by blood transfusion as shown in table- 4 . Only $5.88 \%$ of the cases had an episode of jaundice in the past.

\begin{tabular}{|c|c|c|}
\hline \multicolumn{3}{|c|}{$\begin{array}{c}\text { Table II. Proportion of hepatitis-C amongst total reported } \\
\text { positive cases of hepatitis }\end{array}$} \\
\hline Types of hepatitis & No. of +ve cases & $\%$ age \\
\hline A & 37 & 22.98 \\
\hline B & 70 & 43.47 \\
\hline C & 54 & $* 33.54$ \\
\hline Total & 161 & \\
\hline${ }^{*}$ Cl by Exact Binomial method $=26.303 \%$ to $41.397 \%$ \\
\hline
\end{tabular}

\begin{tabular}{|c|c|c|}
\hline \multicolumn{2}{|c|}{ Table III Sex Distribution of Anti HCV Antigen } \\
\hline Subjects & Anti Hcv +ve & Anti HCV -ve \\
\hline Males $n=797$ & 53 & 744 \\
\hline Females $n=93$ & 01 & 92 \\
\hline \multicolumn{2}{|c|}{ Significance Level $=P<0.05$ (Statistically Significant) } \\
\hline
\end{tabular}

\begin{tabular}{|c|c|c|}
\hline \multicolumn{3}{|c|}{ Table IV Common Modes of Transmission of HCV } \\
Infection
\end{tabular}

\section{DISCUSSION}

HCV infection is the most common blood borne infection and leading cause of chronic liver disease in United States. More than 10,000 deaths annually are caused by HCV infection in USA ${ }^{10}$.

The prevalence rates of anti HCV among blood donors have been reportedly low in most European countries; $0.24 \%$ to $0.79 \%$ in Germany ${ }^{11}, 0.87 \%$ in Italy ${ }^{12}$ and $0.5 \%$ to $1.0 \%$ in U.K $\mathrm{K}^{13}$. But the prevalence rate from Spain has been reported as $7.3 \%$, which is consistent to the result of the present study ${ }^{14}$. The prevalence rate in Far East and China is up to $4.6 \%{ }^{15}$.

A study conducted in United States showed that high rate of HCV infection was associated with a history of cocaine or marijuana use ${ }^{10}$. The females in our study showed a low rate of infection probably because they are less exposed to the risk factors. The results of our study are comparable with the results of other studies carried on blood donors in Pakistan ${ }^{16}$.

More attention should be paid to the preventive measures as patients with chronic HCV infection and advance Liver disease usually have a poor response to treatment. More so the best current medical therapy is expensive, complex, relatively ineffective and fraught with side effects ${ }^{17}$.

We suggest that;

The awareness in the people should be created about the severity of the disease through projection on electronic media so that the spread of this disease can be checked.

Use of conventional glass syringes must be stopped. People should insist on using packed disposable syringes while getting an injection and the used syringe must be properly destroyed.

1. The government should include the vaccination for hepatitis in its expanded immunization programme to save millions of lives.

2. All the blood from the donors should be 
screened for anti HCV.

\section{CONCLUSION}

The results of high prevalence of hepatitis $C$ in the present study underline the dire need of a national comprehensive plan for multi-disciplinary approach for HCV prevention and control. The people engaged in high-risk activities should be provided with risk-reduction counseling services.

\section{REFERENCES}

1. Zuberi SJ. Sero epidemiclogy of HBV/HCV in Pakistan. International Hepatology Communication 1996; 5: 19-26

2. Umar M. Treatment of Chronic Hepatitis C virus infection: At the beginning of new millennium (Editorial) JRMC 1999; 3: 1-3

3. Kuo G, Chool QL, Alter HJ et al. An assay for circulating antibodies to a major etiologic virus of human non-A, non-B hepatitis. Science 1989; $244: 362-4$

4. Asghar AS, Hafiz A. Study of antibodies to hepatitis-C virus in cirrhosis of Liver and hepato-cellular carcinoma, Pak J Med Sc 1995; 12: 47-50.

5. Ali L, Malik H, Shah MA. Hepatitis-C in Chronic Liver disease. Pak J Med Sc 2000; 16: 146-51.

6. Konetz RL, Abbey H, Coleman E, Gitnick G. Non-A, non$B$ post transfusion hepatitis : Looking back in the second decade. Ann Intern Med 1993; $119: 110-5$.

7. Jonas MM. Hepatitis-C infection in children. $N$ Eng $J$ Med 1999; 341: 912-13.
8. Ali M, Noor NA, Safdar MS. Prevalence of HCV antibodies in Haemodialysis Population of Multan Pakistan. Pak J Med Sc 1997; 14: 15-18.

9. Conry-Cantilena C, Van Raden M, Gibble J. et al Routes of Infection, viremia and Liver disease in blood donors found to have hepatitis $\mathrm{C}$ virus infection. $\mathrm{N}$ Eng J Med 1996; 334: 1691-6

10. Alter MJ, Moran DK, Nainan OV et al. The Prevalence of Hepatitis C virus infection in United States, 1988 through 1994. N Eng J Med 1999; 341: 556-62

11. Kunnl P, Seidl S, Stangel W et al. Antibody to Hepatitis C virus in German blood donors. Lancet 1989; 2: 324-6

12. Bellantani $L$, Prevalence of CLD in general population Northern Italy. Hepatology 1994; 20: 1442-9

13. Vander Pool CL et al. HCV six years. Lancet 1994; 344 : $1475-9$.

14. Esteban JI, Esteban R, Viladomill L et al. HCV antibodies among risk groups in Spain. Lancet 1989; 2: 294-7.

15. Matsuoka S, Tatara K, Hayabuchi Y, Nii M, Morik, Kuroda $Y$. Post transfusion Hepatitis-C in children. J. Paed Child Health 1994; 30 : 544-6.

16. Bhatti A., Tariq M. Epidemiology of Hepatitis $C$ virus in blood donors in Northern Pakistan. Pakistan Society of Gastroentrology; 12 - 15 Jan 1996; Pg 68.

17. Healthcote EJ, Shiffman ML, Cooksley WGE et al. Peginterferon Alfa-2 a in patients with chronic hepatitis $C$ and cirrhosis. N Eng J Med 2000; 343: 1673 . 80 . 